\title{
Understanding the impact of chemical conditioning with inorganic polymer flocculants on soluble extracellular polymeric substances in relation to the sludge dewaterability
}

\author{
Weijun Zhang ${ }^{\mathrm{a}}$, Ping Xiao ${ }^{\mathrm{a}}$, Yuanyuan Liu ${ }^{\mathrm{a}}$, Shiwei Xu ${ }^{\mathrm{b}, \mathrm{c}}$, Feng Xiao ${ }^{\mathrm{a}}$, Dongsheng Wang ${ }^{\mathrm{a}, \mathrm{d}, *}$, \\ Christopher W.K. Chow ${ }^{\mathrm{d}}$ \\ a State Key Laboratory of Environmental Aquatic Chemistry, Research Center for Eco-Environmental Sciences, Chinese Academy of Sciences, Beijing 100085, China \\ ${ }^{\mathrm{b}}$ School of Water Resources and Environment, China University of Geosciences, Beijing 100083, China \\ ${ }^{\mathrm{c}}$ Beijing Drainage Group Company Limited, Beijing 100024, China \\ ${ }^{\mathrm{d}}$ SA Water Centre for Water Management and Reuse, School of Natural and Built Environments, University of South Australia, Mawson Lakes, SA 5095, Australia
}

\section{A R T I C L E I N F O}

\section{Article history:}

Received 11 August 2013

Received in revised form 12 May 2014

Accepted 15 May 2014

Available online 2 June 2014

\section{Keywords:}

Chemical conditioning

Inorganic polymer flocculants (IPFs)

Sludge dewatering

Soluble extracellular polymeric substances

(SEPS)

\begin{abstract}
A B S T R A C T
Generally, sludge conditioned with inorganic coagulants exhibits rigid structure and is suitable for high pressure dewatering process. Sludge flocs possess multilayered structure, and the sludge dewaterability is mainly dependent on the properties of soluble extracellular polymeric substances (SEPS). However, few studies have focused on influence of chemical conditioning on the characteristics of SEPS. In this study, the surplus sludge obtained from wastewater treatment plant (WWTP) was conditioned with two inorganic polymer flocculants (IPFs), PACl and HPAC, for improving the sludge dewaterability which was measured using specific resistance to filtration (SRF). Meanwhile, the variation in SEPS properties was investigated with combined high performance size-exclusion chromatography (HPESC) and fluorescence excitation-emission matrix (EEM). According to the experimental results, HPAC showed better performance in improving sludge dewaterability due to higher charge density and better bridging properties. EEM coupled to fluorescence region integration (FRI) demonstrated that protein-like substances were dominant fraction of soluble EPS. HPSEC analysis indicated that most of the SEPS with high molecular weight $(>2000 \mathrm{Da}$ ) were effectively removed from aqueous phase after conditioning, they might play more important roles in sludge dewatering. SRF correlated well with zeta potential, dissolved organic carbon (DOC) and EPS content located in all four EEM regions under chemical conditioning. This result revealed that EEM in conjunction with FRI was an attractive way to evaluate the sludge conditioning efficiency of IPFs.
\end{abstract}

(c) 2014 Elsevier B.V. All rights reserved.

\section{Introduction}

The management of wastewater sludge accounts for a major portion of the cost of the wastewater treatment process and represents significant technical challenges. In many wastewater treatment facilities, the bottleneck of the sludge handling system is dewatering operation. Sludge is very complex colloidal system and consisted of highly dispersed and slimy particles at sizes around $10^{-9} \mathrm{~m}$, thereby making solid-water separation very difficult [1]. Sludge particles are always negatively charged due to ionization of anionic functional groups such as carboxylic and

\footnotetext{
* Corresponding author at: State Key Laboratory of Environmental Aquatic Chemistry, Research Center for Eco-Environmental Sciences, Chinese Academy of Sciences, Beijing 100085, China. Tel./fax: +86 1062849138.

E-mail address: wgds@rcees.ac.cn (D. Wang).
}

phosphate, and form heterogeneous double layer structure. Generally, chemical conditioning is a required step prior to dewatering to achieve the desired efficiency. The application of chemical flocculants helps to increase the sludge particle size by agglomerating the small fines of the sludge colloids, which causes blinding, to form large flocs, which can be more easily separated from the water. The sludge flocs conditioned by organic polyelectrolytes are large and loose [2] and therefore fit for low-pressure dewatering process (centrifuge), while inorganic coagulants conditioning can produce a rigid floc, so they are often used in high-pressure process such as filter press and belt press $[3,4]$.

Extracellular polymeric substances (EPS) are one of the most important constituents of activated sludge, and their molecular weight (MW), chemical nature and structure are of particular importance to contaminants removal and sludge properties [5]. 
EPS is consisted of high MW polysaccharides, proteins, glycoproteins, nucleic acids, phospholipids and humic acids, affecting flocculation, settling and dewatering properties of activated sludge. Recently, multilayered structure model of sludge floc was proposed to understand the relationship between distribution and abundance of EPS and sludge dewaterability. Li et al. reported that EPS in activated sludge floc could be fractionated into loosely bounded EPS (LB-EPS) and tightly bounded EPS (TB-EPS), and the sludge dewatering behavior is mainly governed by characteristics of the former [6,7]. Furthermore, Yu et al. also suggested that sludge flocs were consisted of supernatant (bulk solution), slime, loosely bounded layer, tightly bounded layer and pellets, and sludge dewaterability is primarily influenced by the proteins (PN) and proteins/polysaccharides (PN/PS) in slime and bulk [8]. The organic compounds in the sludge bulk are composed primarily of SEPS $[9,10]$ which is actually soluble microbial products (SMP) according to the report of Laspidou and Rittmann [11]. Fluorescence spectroscopy is proven to be an appropriate and effective method to characterize the EPS of activated sludge floc [12]. Yu et al. used three fluorescence excitation-emission matrix (3DEEM) combined with parallel factor (PARAFAC) analysis to identify the key organic constituents affecting the sludge dewatering property, and the results indicated that the fluorescent intensity of protein-like substances in the bulk fraction correlated well with performance of sludge dewatering [13]. However, it is noted that the formation of EPS in activated sludge is a very complex bioprocess, so it is difficult to elucidate the nature of EPS. Combined EEM fluorescence spectroscopy and molecular weight analysis is able to provide unique and useful information on the better insight into the characteristics of EPS formed in biological process [14].

The influence of chemical conditioning on properties of sludge particles have been reported by many studies, but few of them focused on influence of chemical conditioning (especially inorganic coagulants) on soluble EPS properties. Both organic flocculants and inorganic conditioner can interact with sludge particles through charge neutralization and bridging, while inorganic coagulants should have greater effect on characteristics of SEPS due to their coagulation property. It is generally accepted that polyaluminum chloride (PACl) increases adsorption of organics in the bulk and improves sludge filterability [15]. The coagulation effectiveness of inorganic polymer flocculants (IPFs) is significantly affected by speciation distribution and physicochemical properties. Basically, the IPFs are intermediate compounds obtained from the hydrolysis-polymerization-settlement under artificially intensified conditions, and they are mainly composed by complexes of hydroxyl polynuclear species and various anions. Many studies demonstrated that the pre-formed polyhydroxy polymers exhibited better hydrolysis stability [16]. Therefore, IPFs are able to work more quickly than metal salts of low MW after entering into aqueous solution and show the better performance in coagulation process. In recent years, composite inorganic polymer flocculants are developed with both the advantages of IPFs and the additive coagulant aids, and the additives can improve the charge neutralization and bridging abilities of IPFs [17]. In this study, two IPFs, PACl and composite coagulant (HPAC), were used as sludge conditioners. Characteristics of SEPS were monitored in order to get an insight into relationship between SEPS and sludge dewatering behavior under IPFs conditioning. These results might provide useful information in controlling or optimizing chemical conditioning processes.

\section{Materials and methods}

\subsection{Waste sludge}

Surplus sludge was sampled from sludge return line of membrane bioreactor (MBR) in Northern brook wastewater treatment plant of Beijing. Now the daily wastewater treatment capacity is 100 thousand ton, $40 \%$ of total flow is treated by anaerobic/ anoxic/oxic $(\mathrm{A} / \mathrm{A} / \mathrm{O})$ and other $60 \%$ is reused after treatment by MBR. Sample was stored at $4{ }^{\circ} \mathrm{C}$ and was analyzed within 5 days after sampling. The basic information of waste sludge and bulk can be found in Table 1 .

\subsection{Chemical agents}

The sludge conditioners were two IPFs, polyaluminum chloride ( $\mathrm{PACl}$ ) and a composite coagulant (HPAC). Both coagulants were solutions with $\mathrm{Al}_{2} \mathrm{O}_{3}$ content of $10 \%$ and produced by a local factory (Beijing Wanshui Water Cleaning Agent Co., China). HPAC is made from specially controlled $\mathrm{PACl}$ with high yield of $\mathrm{Al}_{13}$ and different additives during the polymerization process. The basic information of two IPFs is given in Table 2, and the charge property of them is shown in Fig. S1 of Supporting materials (SM).

\subsection{Jar test}

Jar tests were conducted on a programmable jar test equipment (Daiyuan Jar Test Instruments, China). At first, Draw about $400 \mathrm{~mL}$ of sludge into a clean $600 \mathrm{~mL}$ beaker, and tester was started at rapid mixing of $200 \mathrm{rpm}$, coagulant solutions was quickly added followed by a reduction of the mixing speed to $30 \mathrm{rpm}$ for $10 \mathrm{~min}$ and then let it stand for $30 \mathrm{~min}$. Sludge sample was settled down at $2000 \mathrm{~g}$ for $15 \mathrm{~min}$, and the supernatant (bulk solution) was collected as SEPS. Then, zeta potential and turbidity of sludge supernatant was measured. Cellulose acetate (CA) membranes with a pore size of $0.45 \mathrm{~mm}$ were used to remove the particulates present in the sludge supernatant. The filtered fractions were used for analyzing fluorescence EEM and dissolved organic carbon (DOC). In addition, the sample for HPSEC determination was filtered through a $0.22 \mu \mathrm{m}$ membrane.

\subsection{Analytical methods}

\subsection{1. $S R F$}

SRF was measured with the standard Buchner funnel test using a using a quantitative filter paper. It can be obtained by Eq. (1):

$r=\frac{2 P A^{2} b}{\mu \omega}$

where $P\left(\mathrm{~kg} \mathrm{~m}^{-2}\right)$ denotes pressure, $A\left(\mathrm{~m}^{2}\right)$ is filtration area, $\mu$ $\left(\mathrm{kg} \mathrm{s} \mathrm{m}^{-2}\right)$ is kinetic viscosity, $\omega\left(\mathrm{kg} \mathrm{m}^{-3}\right)$ denotes dry solid weight per unit volume sludge on the filtrate media, $b$ is slope of filtration equation- $d t / d V=b V+a$, and $t(\mathrm{~s})$ is time, $V\left(\mathrm{~m}^{3}\right)$ denotes volume of filtrate. The raw and conditioned waste sludge was poured into a

Table 1

Characteristics of waste sludge and sludge bulk.

\begin{tabular}{|c|c|c|c|c|c|c|c|}
\hline \multirow[t]{2}{*}{ Physiochemical characteristics } & \multicolumn{5}{|l|}{ Sludge } & \multicolumn{2}{|l|}{ Sludge bulk } \\
\hline & Solid (\%) & $\mathrm{pH}$ & $\mathrm{ZP}(\mathrm{mV})$ & VSS/TSS & $\mathrm{ZP}(\mathrm{mV})$ & TOC (mg/L) & Turbidity (NTU) \\
\hline Parameters & $1.21 \pm 0.02$ & $7.12 \pm 0.05$ & $-20.6 \pm 2.5$ & $0.63 \pm 0.02$ & $-20.6 \pm 2.5$ & $4.99 \pm 0.03$ & $21.1 \pm 3.2$ \\
\hline
\end{tabular}


Table 2

Basic information of PACl and HPAC.

\begin{tabular}{|c|c|c|c|c|c|c|c|c|}
\hline \multirow[t]{2}{*}{ Reagents } & \multicolumn{3}{|c|}{ Ferron test (\%) } & \multirow[t]{2}{*}{$\mathrm{pH}$} & \multirow[t]{2}{*}{ Water-insoluble solid content (\%) } & \multirow[t]{2}{*}{ Basicity (\%) } & \multirow[t]{2}{*}{$\mathrm{ZP}^{*}(\mathrm{mV})$} & \multirow[t]{2}{*}{ Density $\left(\mathrm{g} / \mathrm{cm}^{3}\right)$} \\
\hline & $\mathrm{Al}_{\mathrm{a}}$ & $\mathrm{Al}_{\mathrm{b}}$ & $\mathrm{Al}_{\mathrm{c}}$ & & & & & \\
\hline $\mathrm{PACl}$ & 31.3 & 16.1 & 52.6 & 4.15 & 0.112 & 55.53 & 42.6 & 1.227 \\
\hline HPAC & 15.6 & 46.8 & 37.6 & 4.43 & 0.089 & 75.14 & 58.0 & 1.223 \\
\hline
\end{tabular}

$\mathrm{ZP}$ of $\mathrm{PACl}$ and HPAC was measured at $\mathrm{pH}=7$.

Buchner funnel with a $0.45 \mu \mathrm{m}$ cellulose acetate membrane to filter under a pressure of $0.6 \mathrm{MPa}$ of vacuum filtration. Volume of filtrate was recorded every $10 \mathrm{~s}$ before surface cracking was observed.

\subsubsection{Fluorescence analysis}

The sample was diluted with Milli Q water until concentration of DOC was below $10 \mathrm{mg} / \mathrm{L}$. The peak locations, peak intensities and the ratios of different peaks in EEM spectra of the EPS samples were not substantially influenced by ionic strength [18]. Threedimensional excitation emission matrix (3-DEEM) spectra were measured by a Hitachi F-4500 fluorescence spectrophotometer with an excitation range from 200 to $400 \mathrm{~nm}$ at $10 \mathrm{~nm}$ sampling intervals and an emission range from 280 to $500 \mathrm{~nm}$ at $10 \mathrm{~nm}$ sampling interval. The spectra were recorded at a scan rate of $12,000 \mathrm{~nm} / \mathrm{min}$, using excitation and emission slit bandwidths of $10 \mathrm{~nm}$. Each scan had 37 emission and 27 excitation wavelengths.

\subsubsection{High performance size-exclusion chromatography analysis (HPSEC)}

Molecule weight (MW) analysis was conducted according to procedure described by Wang [19]. MW was measured by a Waters liquid chromatography system which was consisted of Waters 2487 Dual $\lambda$ Absorbance Detector, Waters 1525 pump system. A Shodex KW 802.5 column (Shoko, Japan) was used for separation. The mobile phase, Milli Q water buffered with $5 \mathrm{mM}$ phosphate to $\mathrm{pH} 6.8$, and $0.01 \mathrm{M} \mathrm{NaCl}$, was filtered through a $0.22 \mu \mathrm{m}$ membrane, and then degassed for 30 min by means of ultrasonication for $0.5 \mathrm{~h}$ before being used to the column. $600 \mu \mathrm{L}$ sample was injected at a flow rate of $0.8 \mathrm{~mL} \mathrm{~min}^{-1}$. Polystyrene sulfonate standards (Sigma-Aldrich, USA) of molecular weights 1.8-32 kDa were used for apparent molecular weight (AMW) calibration.

\subsubsection{Other analytic methods}

Zeta potential and turbidity was measured using Zetasizer2000 (Malvern Instruments Ltd, Malvern, UK) and $2100 \mathrm{~N}$ Turbidimeter (Hach, USA) respectively. The dissolve organic carbon (DOC) of SEPS was analyzed using TOC analyzer (Shimadzu, Kyoto, Japan). pH was measured by a pHS-3C (Shanghai, China) pH meter, which was calibrated using $\mathrm{pH} 7.01$ and $\mathrm{pH} 9.18$ buffers.

\subsubsection{Statistical analysis}

Peak fitting software (Version 4, Systat Software) was used to resolve the overlapped peaks of HPSEC contours. The peak fitting parameters were chosen according to Ref. [20]. The peak area under each resolved peak of water samples was subsequently determined after peak fitting. Fluorescence regional integration (FRI) was analyzed according to the method of Chen et al., which was used to describe the volumetric percentage of a given EEM peak in all the EEM spectra [21]. Correlation analysis was carried out using the software SPSS version 14.0 for Windows (SPSS). Pearson's correlation coefficient $(R)$ was used to evaluate the linear correlation between physicochemical indicators and SRF. Pearson's coefficient is always between -1 and +1 , where -1 denotes a perfect negative correlation, +1 a perfect positive correlation, and 0 the absence of a relationship. The correlations were considered statistically significant at a 95\% confidence interval $(p<0.05)$.

\section{Results and discussion}

\subsection{Effect of chemical conditioning with PACl and HPAC on Zeta potential and $S R F$}

Zeta potential of raw sludge supernatant was $-21.6 \mathrm{mV}$. Addition of the coagulants could eliminate the negative surface charge of the sludge particles by charge neutralization and interparticle bridging, resulting in particle destabilization and aggregation. Upon the addition of PACl and HPAC at the dosage of 15\% and $10 \%$ (g/g dry solid (DS)), zeta potential increased to zero, and then stabilized at around $2 \mathrm{mV}$ with further increase in coagulants dosages (see in Fig. 1). According to the value of SRF, sludge can be classified into the sludge with bad dewaterability $\left(>10^{12}-10^{18}\right.$ $\left.\mathrm{m} \mathrm{kg}^{-1}\right)$, medium dewaterability $\left((5-9) \times 10^{11} \mathrm{~m} \mathrm{~kg}^{-1}\right)$ and good dewaterability $\left(<4 \times 10^{11} \mathrm{~m} \mathrm{~kg}^{-1}\right)$ [22]. As depicted in Fig. 2, the sludge dewaterability was significantly improved after conditioning. SRF was reduced to $2.08 \times 10^{11}$ and $3.98 \times 10^{11} \mathrm{~m} \mathrm{~kg}^{-1}$ (easy to dewater) when PAC and HPAC at the dosage of $5 \%$ and $15 \%(\mathrm{~g} /$ g DS) was applied respectively. It is also found that HPAC showed much better performance than PACl in decreasing the SRF, meaning that that the required dosage to achieve a desired SRF for HPAC was only $30 \%$ of $\mathrm{PACl}$ concentration. The difference in performance of $\mathrm{HPAC}$ and $\mathrm{PACl}$ can be attributed to Al species distributions and chemical additives. Based on reaction rate with Ferron reagent, $\mathrm{Al}$ in $\mathrm{PACl}$ can be divided into three species: $\mathrm{Al}_{\mathrm{a}}, \mathrm{Al}_{\mathrm{b}}$ and $\mathrm{Al}_{\mathrm{c}}[16] . \mathrm{Al}_{\mathrm{b}}$ carries much higher positive charge density in comparison to other two species. HPAC exhibits $30 \% \mathrm{Al}_{\mathrm{b}}$ content more than $\mathrm{PACl}$ (Table 2), so HPAC was more effective in charge neutralization. Again, since the organic additives could enhance the charge neutralization and bridging properties of $\mathrm{PACl}$ [17], sludge floc obtained from HPAC conditioning exhibited more compact structure (higher fractal dimension) and larger particle size (see in Fig. S2 of SM). Interestingly, deterioration of sludge dewaterability was observed as organic flocculants were overdosed due to the

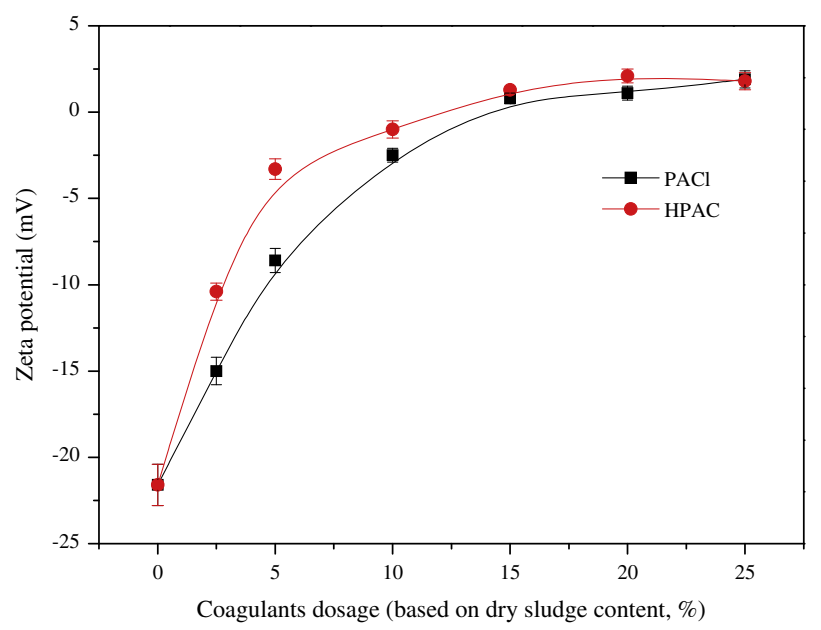

Fig. 1. Effect of chemical conditioning with PACl and HPAC on the ZP 


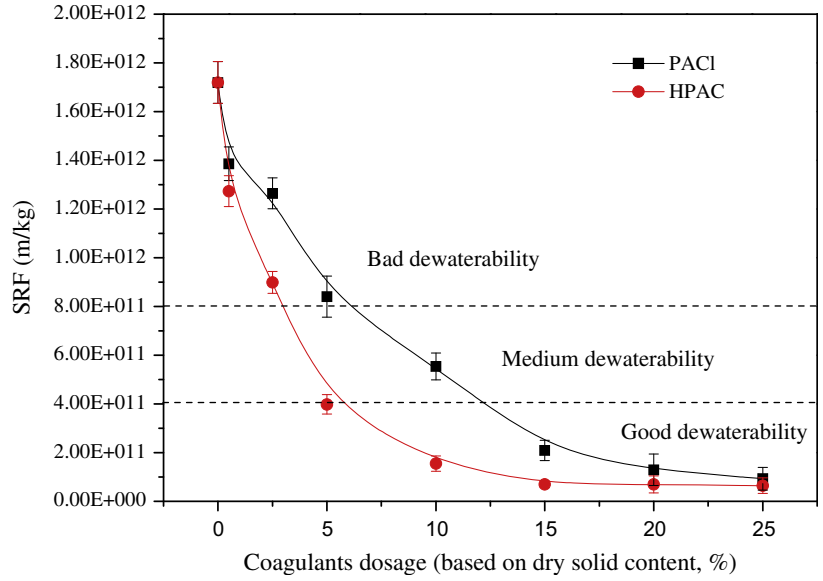

Fig. 2. Effect of chemical conditioning with PACl and HPAC on SRF.

presence of unabsorbed polyelectrolyte in the aqueous phase, which consequently increased the viscosity of sludge [23]. But it did not occur with continued increase in dosage of two IPFs used in this study.

\subsection{Variation in DOC and turbidity in sludge bulk with conditioning by IPFs}

SEPS are the main constituents of colloidal particles. Inorganic coagulants could result in destabilization and aggregation of sludge particles by charge neutralization and bridging, hence the SEPS would transfer from aqueous phase to solid phase through coagulation-precipitation process. Fig. 3(A) and (B) present the influence of IPFs conditioning on turbidity and DOC respectively. Turbidity reduced and reached the minimum 4.3 and 2.7 at the dosages of $10 \%$ for HPAC and $15 \%$ (g/g DS) for PACl, and then went up with further increase in dosage of both coagulants. Turbidity in sludge supernatant originated from biocolloid matters, such as polysaccharides and proteins with high MWs. Addition of $\mathrm{PACl}$ and HPAC would destabilize and remove colloid matters through charge neutralization and absorption. Overdosed coagulants produced surplus positive charge and resulted in restabilization of colloidal system, thus turbidity of sludge supernatant was increased. Removal of DOC was enhanced with increase in dosage of both coagulants. It was very likely that the removal of $\mathrm{DOC}$ at $\mathrm{pH}=7$ was entirely attributed to adsorption on precipitated aluminum hydroxide.

\subsection{Influence of chemical conditioning on soluble EPS with different molecule weights}

Based on the relationship between elution time and apparent molecule weight (AMW) of the sodium polystyrene sulfonate standards, the MW distribution of the ultraviolet (UV) was classified. Since carbohydrates do not have double bonds needed for the absorption of UV light, the detection of carbohydrates was only possible if they were present as part of molecule complexes, such as glycoproteins and glycolipids [24]. Fig. 4 presented that seven peaks were identified in HPSEC profile of raw sludge bulk. The apparent molecular weights (AMW) of the resolved peaks were calculated to be 316 Da (Peak1), 870 Da (Peak 2), 1500 Da (Peak 3), $2200 \mathrm{Da}$ (Peak 4), $3000 \mathrm{Da}$ (Peak 5), 4100 (Peak 6) and $43,000 \mathrm{Da}$ (Peak 7) respectively. The organic matters can be divided into three fractions: macromolecular fraction (>5000 Da) - mainly consisting of carbohydrates and proteins [25], low molecular fraction (0-5000 Da) - consisting of humic substances and
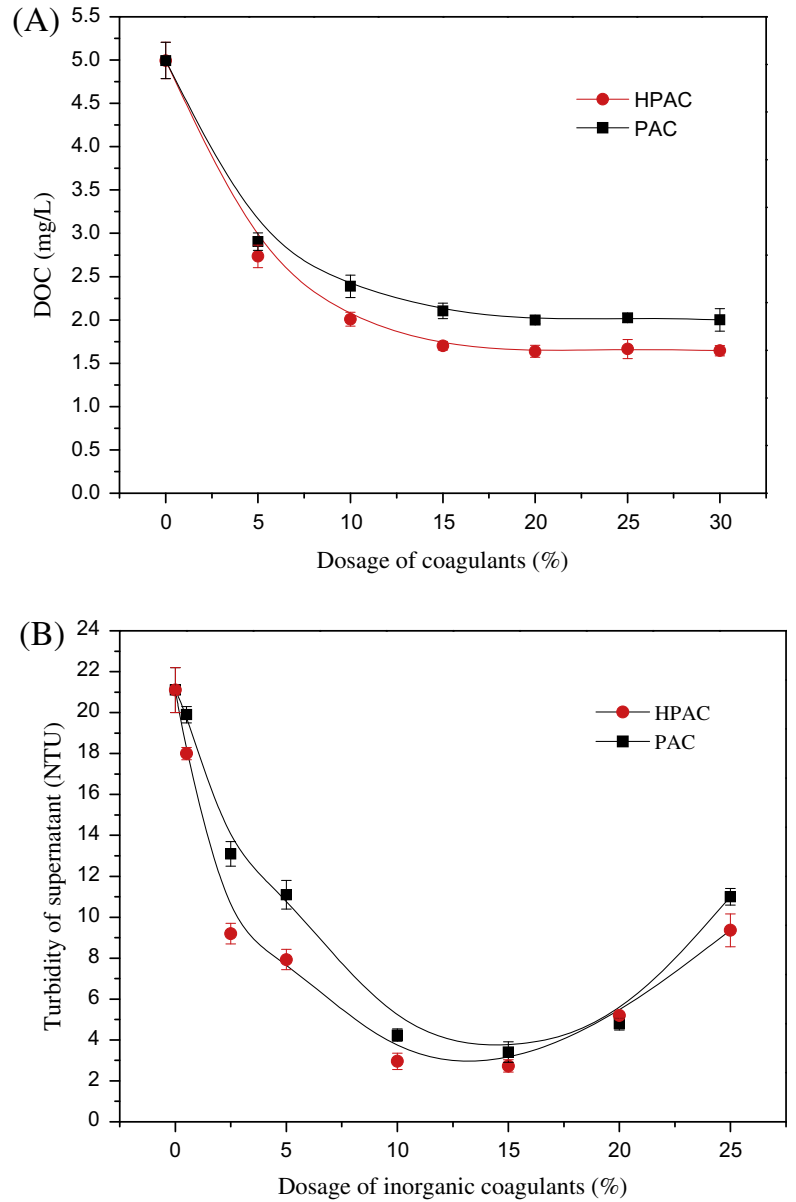

Fig. 3. Influence of chemical conditioning by inorganic coagulants on DOC (A) and turbidity (B) in sludge bulk.

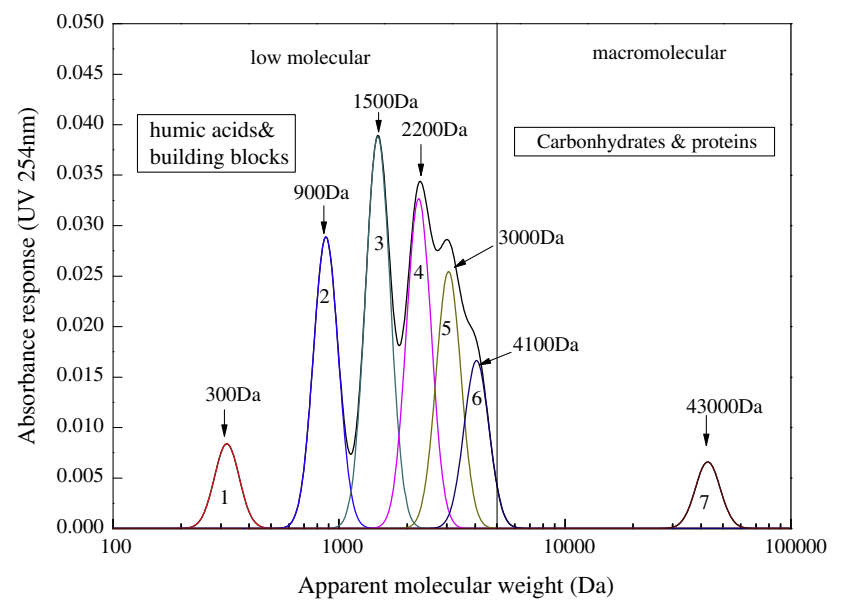

Fig. 4. DOM molecular weight profiles of raw sludge bulk with peak fitting.

building blocks $[10,25]$. As depicted in Fig. 5, sharp decrease in areas of all peaks was observed after the use of both conditioners at the dosage of $10 \%$ (g/g DS). Intensity of peak 5 was greatly weakened, and peak 6 and peak 7 almost disappeared after chemical conditioning. Other peaks (peak 1, peak 2 and peak 3 and peak 4) were partially removed and remained unchanged with further addition of coagulants. Apparently, the larger organic matters ( $\mathrm{MW}>2000 \mathrm{Da}$ ) were easier to be removed after conditioning. This observation is in agreement to the finding of Zhang et al., who 


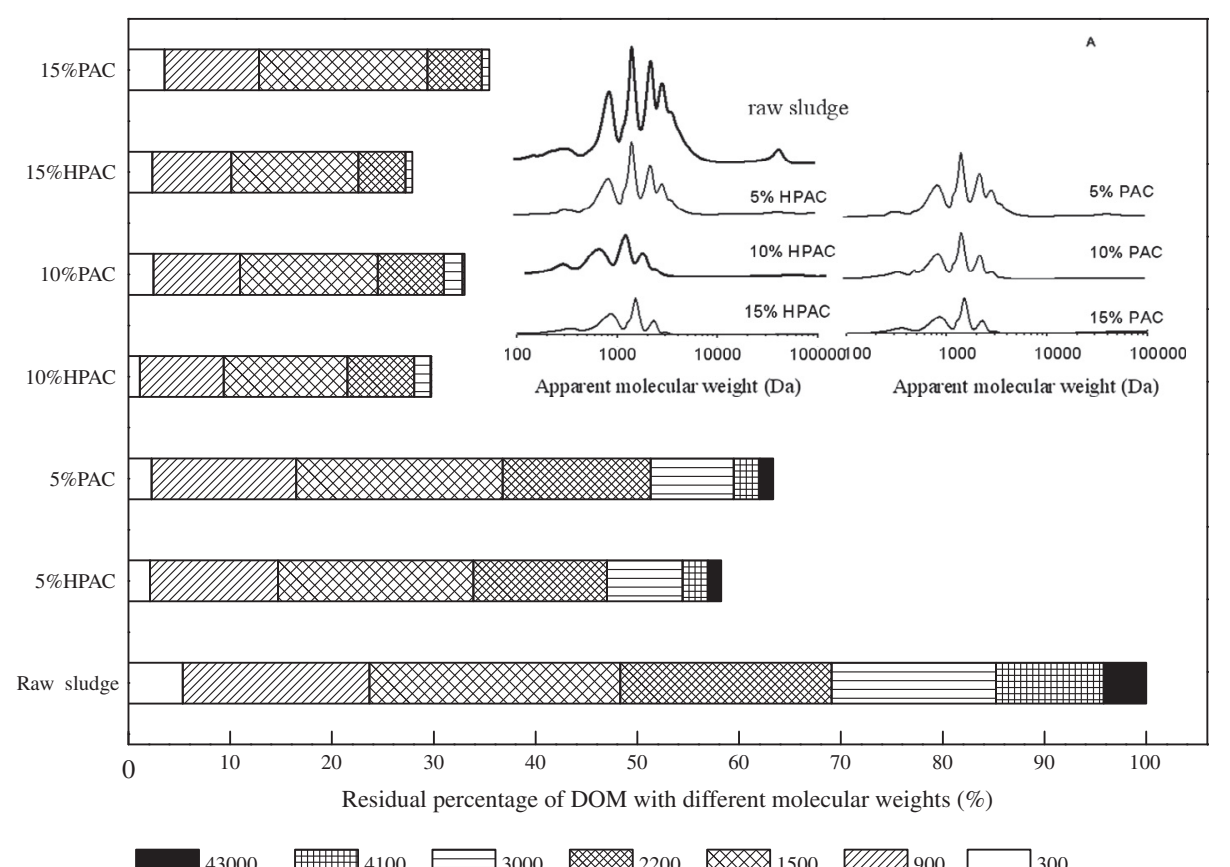

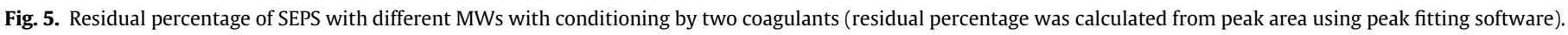

stated that the addition of ferric chloride at the optimal concentration could reduce both SEPS with MW more than $10 \mathrm{kDa}$ in the supernatant [26]. High MW biopolymers are produced by microorganisms during substrate metabolism and/or released during cell lysis and decay. They had much more significant influence on membrane flux and have been widely accepted as a major factor resulting in membrane fouling [27]. Wang et al. found high MW molecules, in particular over 1,869.7 kDa, could not be detected in membrane effluent due to retention effects of the membrane and to the adsorption of the gel layer formed on membrane surfaces, while they were observed in conventional activated sludge (CAS) process $[28,29]$. Additionally, the high MW molecules might aggregate into larger colloidal particles in the MBR, which would greatly deteriorate the filterability of the MBR sludge in comparison to the CAS sludge [30]. Lyko et al. reported that the dewaterability of activated sludge was significantly affected by dissolved macromolecular compounds [24], which are more likely to block the filter medium [31], thereby increasing filtration resistance of sludge. Many studies reported that addition of an optimum coagulants concentration could lead to lower SEPS content, lower hydrophobicity, lower concentration of filamentous bacteria and better bioflocculation property, which resulted in the decrease in cake layer resistance and pore blocking resistance [26,32].

\subsection{Effect of chemical conditioning on EEM fluorescence spectra of sludge bulk}

EEM spectroscopy has been proven to be an appropriate and effective method to characterize the EPS from various origins in wastewater treatment systems [18]. Each EEM gives spectral information about the chemical compositions of EPS samples. SEPS-EEM fluorescence spectra of raw sludge bulk are acquired and shown in (see Fig. S3 of SM). The peaks located at the excitation/emission wavelengths (Ex/Em) of 225.0/350.0 nm and 275.0/350.0 nm indicate aromatic protein-like substances (APN) and tryptophan protein-like substances (TPN), respectively. The peaks at 335.0/ $420.0 \mathrm{~nm}$ and $235.0 / 415.0 \mathrm{~nm}$ are associated with humic-like acids (HA) and fulvic-like acids (FA) respectively [21]. Naomi et al. used fluorescence spectrometry as a tool for water quality analysis, since the intensity of the peak can represent the concentration of fluorophores [33]. At a low EPS concentration (e.g., DOC $<10 \mathrm{mg} /$ $\mathrm{L}$ ), the fluorescent intensity had a linear relationship with the EPS concentration [18]. APN, TPN, HA and FA in raw sludge liquor accounted for $44.27 \%, 35.69 \%, 13.22 \%$ and $6.81 \%$ of the total respectively. Apparently, protein-like matters were the dominant fraction of SEPS, this result was in accordance with that of report of Mikkelsen and Keiding [34]. The aromatic proteins were more prone to accumulate within the fouling layer than tryptophan proteins, which is possibly due to the hydrophobic nature of aromatic proteins [25]. High content protein-like compounds might originate from the decayed biomass due to long sludge retention time (SRT) of MBR [35]. The fluorescence peak locations were not affected by chemical conditioning, while the fluorescence intensity was decreased (see Figs. S4 and S5 of SM). As shown in the inset of Fig. 6(A) and (C), the influence of chemical conditioning on dissolved organic matters located in different EEM regions showed a very similar pattern. The normalized DOC of APN, TPN, HA and FA was reduced as the inorganic coagulants increased from $5 \%$ to $15 \%$ (g/g DS), but the concentration did not proceed apparently with further increase in dosage of inorganic coagulants. Fig. 6(B) and (D) shows that the proportion of humic acids slightly increased with the addition of two conditioners while that of total protein content decreased. This finding revealed that protein-like compounds were more easily removed by coagulation due to a high affinity of proteins for the metal ions. EEM in conjunction with the MW analysis indicated that the high MW organic matters (such as carbohydrates and proteins) might play more important role in sludge dewatering process.

Correlation analysis was performed to get insight into the relationship between the SEPS properties and sludge dewaterability under chemical conditioning. As showed in Tables 3 and 4, significant correlation was found between SRF and DOC, ZP, APN, TPN, HA and FA. Especially, a strong correlation existed between SRF and ZP $\left(R^{2}=0.99, p<0.01\right)$, HA content $\left(R^{2}>0.9, p<0.01\right)$ during chemical conditioning by two inorganic coagulants. This result reflected that the improvement of sludge dewatering performance 

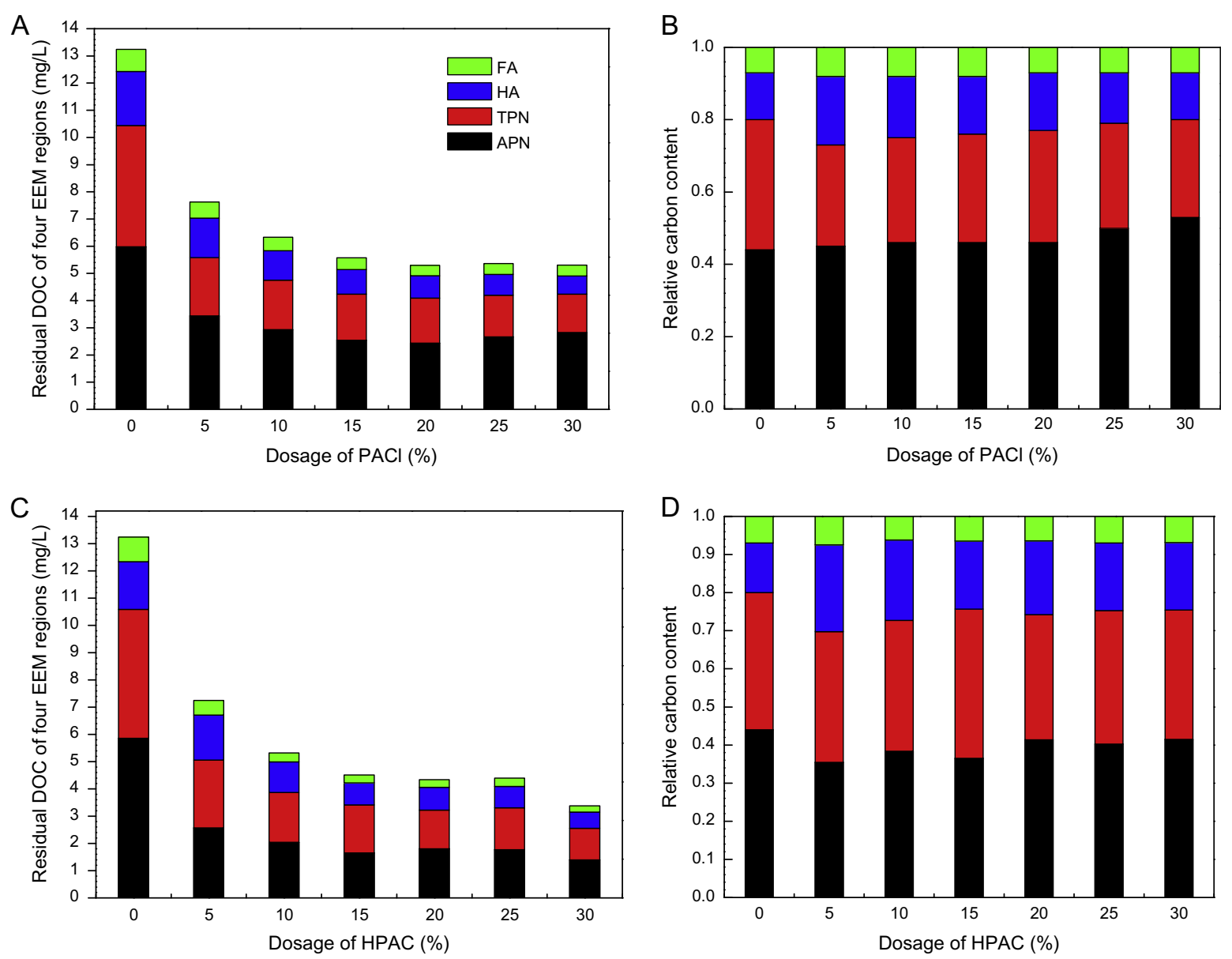

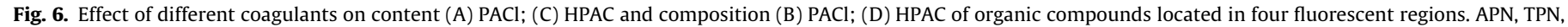
$\mathrm{HA}$ and FA are the abbreviations of aromatic proteins, tryptophan proteins, humic acids and fulvic acids respectively.

was mainly attributed to charge neutralization of inorganic coagulants, and humic acids was very likely to carry the highest negative charge, even though its content was lower than proteins. Yu et al. found that SRF correlated well with protein and mass ratio of protein/polysaccharide in sludge bulk, slime, and LB-EPS, but rather than PN and PN/PS in the pellet and the sludge flocs as a whole [8]. Rosenberger and Kraume [36] also suggested that filterability of the activated sludge was primarily influenced by soluble EPS rather than extracted EPS with cation exchange resin. The strong correlation between SRF and HA\&FA indicated protein-like substances were not the only constituent affecting sludge dewaterability, the HA and FA also played important roles in sludge dewatering process. Furthermore, Houghton [37] and Yuan and Zydney [38] demonstrated that humic and fulvic acids were the most important contributing factors to the membrane filtration resistance. This can be reflected by fact that the dewaterability of
Table 4

Pearson correlation between SRF and characteristics of sludge bulk with chemical conditioning by HPAC.

\begin{tabular}{llllllll}
\hline & SRF & TOC & ZP & APN & TPN & HA & FA \\
\hline SRF & 1 & $0.785^{*}$ & $-0.995^{* *}$ & 0.750 & $0.814^{*}$ & $0.918^{* *}$ & $0.804^{* *}$ \\
TOC & $0.785^{*}$ & 1 & $-0.814^{*}$ & $0.993^{* *}$ & $0.992^{* *}$ & $0.845^{*}$ & $0.987^{* *}$ \\
ZP & $-0.995^{* *}$ & $-0.814^{*}$ & 1 & -0.794 & $-0.835^{*}$ & $-0.916^{*}$ & -0.795 \\
APN & 0.750 & $0.993^{* *}$ & -0.794 & 1 & $0.988^{* *}$ & $0.811^{*}$ & $0.977^{* * *}$ \\
TPN & $0.814^{*}$ & $0.992^{* *}$ & $-0.835^{*}$ & $0.988^{* *}$ & 1 & $0.861^{*}$ & $0.989^{* *}$ \\
HA & $0.918^{* *}$ & $0.845^{*}$ & $-0.916^{*}$ & $0.811^{*}$ & $0.861^{*}$ & 1 & $0.901^{* *}$ \\
FA & $0.804^{*}$ & $0.987^{* *}$ & -0.795 & $0.977^{* *}$ & $0.989^{* *}$ & $0.901^{* *}$ & 1 \\
\hline
\end{tabular}

* Correlation is significant at the 0.05 level (2-tailed).

Correlation is significant at the 0.01 level (2-tailed).

anaerobic digested sludge is known to be worse than that of fresh or aerobic sludge, and decomposition of protein and carbohydrate

Table 3

Pearson correlation between SRF and characteristics of sludge bulk with chemical conditioning by PACl.

\begin{tabular}{|c|c|c|c|c|c|c|c|}
\hline & SRF & TOC & ZP & APN & TPN & HA & FA \\
\hline SRF & 1 & $0.909^{* * *}$ & $-0.987^{* *}$ & $0.849^{*}$ & $0.854^{*}$ & $0.978^{* * *}$ & $0.958^{*}$ \\
\hline TOC & $0.909^{* *}$ & 1 & $-0.891^{*}$ & $0.976^{* *}$ & $0.988^{* *}$ & $0.973^{* * *}$ & $0.985^{*}$ \\
\hline $\mathrm{ZP}$ & $-0.987^{* *}$ & $-0.891^{*}$ & 1 & $-0.836^{*}$ & $-0.874^{*}$ & $-0.947^{* *}$ & $-0.923^{*}$ \\
\hline APN & $0.849^{*}$ & $0.976^{* *}$ & $-0.836^{*}$ & 1 & $0.984^{* *}$ & $0.923^{* *}$ & $0.963^{*}$ \\
\hline TPN & $0.854^{*}$ & $0.988^{* * *}$ & $-0.874^{*}$ & $0.984^{* *}$ & 1 & $0.934^{* * *}$ & $0.957^{*}$ \\
\hline $\mathrm{HA}$ & $0.978^{* *}$ & $0.973^{* *}$ & $-0.947^{* *}$ & $0.923^{* *}$ & $0.934^{* *}$ & 1 & $0.990^{*}$ \\
\hline FA & $0.958^{* * *}$ & $0.985^{* *}$ & $-0.923^{* *}$ & $0.963^{* *}$ & $0.957^{* *}$ & $0.990^{* *}$ & 1 \\
\hline
\end{tabular}

\footnotetext{
* Correlation is significant at the 0.05 level (2-tailed)
}

** Correlation is significant at the 0.01 level (2-tailed). 
and accumulation of humic substances were observed in this process $[5,39,40]$.

Content and composition of SEPS was closely related to operating conditions and influent quality of WWTPs, such as SRT, HRT, dissolved oxygen, feed strength and carbon/nitrogen $(\mathrm{C} / \mathrm{N})$ ratio. Therefore, it is possible for the operator of WWTPs to regulate the operating parameters to reduce the production of SEPS and provide a sludge with good dewaterability. For example, a certain optimum range of HRT and SRT exists in which it is possible to obtain minimum values of SEPS. Barker and Stuckey suggested that when SEPS production was plotted against SRT and HRT, it appeared to decrease to a minimum and then increase again, indicating the existence of an optimal SRT and HRT for minimizing the SEPS production [22]. Furthermore, anaerobic storage of activated sludge, which often takes place at wastewater treatment plants before dewatering, causes a breakage of sludge and release of SEPS, consequently a deterioration of the sludge dewatering property $[39,40]$. Therefore, it is very likely that shortening the anaerobic storage period can avoid sludge decay and maintain good dewaterability.

\section{Conclusions}

In this study, the waste sludge obtained from WWTP was conditioned with two inorganic polymer flocculants (IPFs). HPAC was more efficient than $\mathrm{PACl}$ in improving sludge dewaterability due to higher positive charge density and better bridging properties. The organic compounds with high MW regardless of their chemical nature were easier to be removed by coagulation, they played more important role in sludge dewatering process. Strong correlation was found between concentrations of organic matters located in all four EEM regions, hence 3DEEM analysis coupled to FRI is an attractive way to evaluate the effect of conditioning by inorganic coagulants. Except for proteins-like substances, sludge dewaterability was also influenced by humic acid-like and fulvic acid-like substances in sludge bulk.

\section{Acknowledgement}

The authors gratefully acknowledge the financial support received for this study from the State Water Project for Integrated Water Supply Sludge Quality and Depth of Dewatering Technology (No. 2012ZX07408001-05) and the National Basic Research Program of China under 2011CB933700.

\section{Appendix A. Supplementary material}

Supplementary data associated with this article can be found, in the online version, at http://dx.doi.org/10.1016/j.seppur.2014.05. 034.

\section{References}

[1] K. Roberts, O. Olsson, Influence of colloidal particles on dewatering of activated-sludge with polyelectrolyte, Environ. Sci. Technol. 9 (1975) 945-948.

[2] I.M.C. Lo, K.C.K. Lai, G.H. Chen, Salinity effect on mechanical dewatering of sludge with and without chemical conditioning, Environ. Sci. Technol. 35 (2001) 4691-4696.

[3] Y. Qi, K.B. Thapa, A.F.A. Hoadley, Application of filtration aids for improving sludge dewatering properties - a review, Chem. Eng. J. 171 (2011) 373-384.

[4] M. Niu, W. Zhang, D. Wang, Y. Chen, R. Chen, Correlation of physicochemical properties and sludge dewaterability under chemical conditioning using inorganic coagulants, Bioresour. Technol. 144 (2013) 337-343.

[5] Y. Liu, H.H.P. Fang, Influences of extracellular polymeric substances (EPS) on flocculation, settling, and dewatering of activated sludge, Crit. Rev. Environ. Sci. Technol. 33 (2003) 237-273.

[6] S.F. Yang, X.Y. Li, Influences of extracellular polymeric substances (EPS) on the characteristics of activated sludge under non-steady-state conditions, Proc. Biochem. 44 (2009) 91-96.
[7] X.Y. Li, S.F. Yang, Influence of loosely bound extracellular polymeric substances (EPS) on the flocculation, sedimentation and dewaterability of activated sludge, Water Res. 41 (2007) 1022-1030.

[8] G.-H. Yu, P.-J. He, L.-M. Shao, P.-P. He, Stratification structure of sludge flocs with implications to dewaterability, Environ. Sci. Technol. 42 (2008) $7944-$ 7949.

[9] B.N. Tsai, C.H. Chang, D.J. Lee, Fractionation of soluble microbial products (Smp) and soluble extracellular polymeric substances (Eps) from wastewater sludge, Environ. Technol. 29 (2008) 1127-1138.

[10] S. Lyko, D. Al-Halbouni, T. Wintgens, A. Janot, J. Hollender, W. Dott, T. Melin Polymeric compounds in activated sludge supernatant characterisation and retention mechanisms at a full-scale municipal membrane bioreactor, Water Res. 41 (2007) 3894-3902.

[11] C.S. Laspidou, B.E. Rittmann, A unified theory for extracellular polymeric substances, soluble microbial products, and active and inert biomass, Water Res. 36 (2002) 2711-2720.

[12] R.K. Henderson, A. Baker, K.R. Murphy, A. Hamblya, R.M. Stuetz, S.J. Khan, Fluorescence as a potential monitoring tool for recycled water systems: a review, Water Res. 43 (2009) 863-881.

[13] G.-H. Yu, P.-J. He, L.-M. Shao, Novel insights into sludge dewaterability by fluorescence excitation-emission matrix combined with parallel factor analysis, Water Res. 44 (2010) 797-806.

[14] B.-J. Ni, F. Fang, W.-M. Xie, M. Sun, G.-P. Sheng, W.-H. Li, H.-Q. Yu, Characterization of extracellular polymeric substances produced by mixed microorganisms in activated sludge with gel-permeating chromatography, excitation-emission matrix fluorescence spectroscopy measurement and kinetic modeling, Water Res. 43 (2009) 1350-1358.

[15] Y. Satyawali, M. Balakrishnan, Effect of PAC addition on sludge properties in an MBR treating high strength wastewater, Water Res. 43 (2009) 1577-1588.

[16] H.X. Tang, Inorganic Polymer Flocculation Theory and Flocculants, China Architecture \& Building Press, 2006.

[17] M.Q. Yan, D.S. Wang, J.H. Qu, J.R. Ni, C.W.K. Chow, Enhanced coagulation for high alkalinity and micro-polluted water: the third way through coagulant optimization, Water Res. 42 (2008) 2278-2286.

[18] G.P. Sheng, H.Q. Yu, Characterization of extracellular polymeric substances of aerobic and anaerobic sludge using three-dimensional excitation and emission matrix fluorescence spectroscopy, Water Res. 40 (2006) 1233-1239.

[19] D.S. Wang, L.N. Xing, J.K. Xie, C.W.K. Chow, Z.Z. Xu, Y.M. Zhao, M. Drikas, Application of advanced characterization techniques to assess DOM treatability of micro-polluted and un-polluted drinking source waters in China, Chemosphere 81 (2010) 39-45.

[20] C.W.K. Chow, R. Fabris, J. van Leeuwen, D.S. Wang, M. Drikas, Assessing natural organic matter treatability using high performance size exclusion chromatography, Environ. Sci. Technol. 42 (2008) 6683-6689.

[21] W. Chen, P. Westerhoff, J.A. Leenheer, K. Booksh, Fluorescence excitation emission matrix regional integration to quantify spectra for dissolved organic matter, Environ. Sci. Technol. 37 (2003) 5701-5710.

[22] D.J. Barker, D.C. Stuckey, A review of soluble microbial products (SMP) in wastewater treatment systems, Water Res. 33 (1999) 3063-3082.

[23] C.H. Lee, J.C. Liu, Enhanced sludge dewatering by dual polyelectrolytes conditioning, Water Res. 34 (2000) 4430-4436.

[24] S. Lyko, T. Wintgens, D. Al-Halbouni, S. Baumgarten, D. Tacke, K. Drensla, A. Janot, W. Dott, J. Pinnekamp, T. Melin, Long-term monitoring of a full-scale municipal membrane bioreactor - Characterisation of foulants and operational performance, J. Membrane. Sci. 317 (2008) 78-87.

[25] F.G. Meng, Z.B. Zhou, B.J. Ni, X. Zheng, G.C. Huang, X.S. Jia, S.Y. Li, Y. Xiong, M. Kraume, Characterization of the size-fractionated biomacromolecules: tracking their role and fate in a membrane bioreactor, Water Res. 45 (2011) 4661-4671.

[26] H.F. Zhang, B.S. Sun, X.H. Zhao, Z.H. Gao, Effect of ferric chloride on fouling in membrane bioreactor, Sep. Purif. Technol. 63 (2008) 341-347.

[27] E. Filloux, H. Gallard, J.P. Croue, Identification of effluent organic matter fractions responsible for low-pressure membrane fouling, Water Res. 46 (2012) 5531-5540.

[28] Z. Wang, Z. Wu, Distribution and transformation of molecular weight of organic matters in membrane bioreactor and conventional activated sludge process, Chem. Eng. J. 150 (2009) 396-402.

[29] Z. Wang, Z. Wu, X. Yin, L. Tian, Membrane fouling in a submerged membrane bioreactor (MBR) under sub-critical flux operation: membrane foulant and gel layer characterization, J. Membrane. Sci. 325 (2008) 238-244.

[30] R. Elshereef, H. Budman, C. Moresoli, R.L. Legge, Probing protein colloidal behavior in membrane-based separation processes using spectrofluorometric Rayleigh scattering data, Biotechnol. Progr. 26 (2010) 772-780.

[31] B.H. Guan, J. Yu, H.L. Fu, M.H. Guo, X.H. Xu, Improvement of activated sludge dewaterability by mild thermal treatment in $\mathrm{CaCl}_{2}$ solution, Water Res. 46 (2012) 425-432.

[32] F. Meng, S.-R. Chae, A. Drews, M. Kraume, H.-S. Shin, F. Yang, Recent advances in membrane bioreactors (MBRs): membrane fouling and membrane material, Water Res. 43 (2009) 1489-1512.

[33] N. Hudson, A. Baker, D. Ward, D.M. Reynlds, C. Brunsdon, C. Carliell-Marquet, S. Browning, Can fluorescence spectrometry be used as a surrogate for the Biochemical Oxygen Demand (BOD) test in water quality assessment? An example from South West England, Sci. Total Environ. 391 (2008) 149-158.

[34] L.H. Mikkelsen, K. Keiding, Physico-chemical characteristics of full scale sewage sludges with implications to dewatering, Water Res. 36 (2002) 2451-2462. 
[35] H.S. Shin, S.T. Kang, Characteristics and fates of soluble microbial products in ceramic membrane bioreactor at various sludge retention times, Water Res. 37 (2003) 121-127.

[36] S. Rosenberger, M. Kraume, Filterability of activated sludge in membrane bioreactors, Desalination 151 (2003) 195-200.

[37] J.I. Houghton, J. Quarmby, T. Stephenson, Municipal wastewater sludge dewaterability and the presence of microbial extracellular polymer, Water Sci. Technol. 44 (2001) 373-379.
[38] W. Yuan, A.L. Zydney, Humic acid fouling during ultrafiltration, Environ. Sci. Technol. 34 (2000) 5043-5050.

[39] P.H. Nielsen, B. Frølund, K. Keiding, Changes in the composition of extracellular polymeric substances in activated sludge during anaerobic storage, Appl. Microbiol. Biotechnol. 44 (1996) 823-830.

[40] Z. Lei, X. Luo, Z. Zhang, N. Sugiura, Effects of variations of extracellular polymeric substances and soluble microbial products on activated sludge properties during anaerobic storage, Environ. Technol. 28 (2007) 529-544. 